\title{
初中语文课教学的新路径 以读促写,读写结合
}

冯春玲

辽宁省沈阳市辉山学校

DOI:10.32629/jief.v2i4.1256

[摘 要] 阅读和写作都是初中语文教学的重点, 学生通过阅读能够认知外界, 获取丰富的知识涵养, 而写作则是对这些知识涵养进行二次加 工的过程, 两者一进一出, 相辅相成, 对于提高学生的语文素养都有重要的意义。然而, 在大多数初中语文教学课堂上, 由于受教学大纲和 教学目标的限制, 导致 “以读促写” 这一伟大教学理念很难顺利实施, 导致原本阅读教学中的大量教学营养无法得到正确的利用, 这就是奠 定的教学资源浪费。阅读是写作的基础, 将两者进行有积结合, 通过阅读的力量来带动学生写作能力的提升, 既能使学生的阅读能力、感悟 能力得到有效的提升, 另一方面学生的创造力也能得到大幅度的提高, 一举两得。本文立足初中语文教学实际, 针对如何在初中语文中开展 “以读促写”教学活动提出几点浅薄的以供各位同仁参考。

[关键词] 初中语文; 读写结合; 以读促写

中图分类号：G633.3 文献标识码：A

大量有效的阅读是提高学生写作能力的根本。多年教学经验, 笔者 发现, 初中生在写作过程中, 经常犯的两个错误, 一个是词语和语句不 够精炼, 这时典型素材不足的一种表现, 另一个方面就是, 写作过于平 凹, 缺乏情感的起伏, 既不能打动自己, 也不能打动被人, 这是无法合 理运用内在情感的一种。大量的阅读就是积累语句和素材的重要方式, 而有效的阅读, 则是学生得到情感升华, 获取灵感的重要一环。因此, 在初中语文教学中开展 “以读促写” 教学活动, 既能有效提高学生的阅 读能力, 也能巧妙提高学生的写作水平, 读中有写, 写中有读, 两者平 稳提升, 一举两得。

\section{1 初中语文教学中开展以读促写活动需要注意的几点}

在初中语文教学中开展 “以读促写” 教学活动的唯一宗旨就是：探 寻一条符合当代初中生语文学习发展的道路, 通过巧妙地利用课本上的 课文资源, 来有效激发学生的创作灵感, 从而提高全体学生的写作能力。

值得注意的是, 在日常进行阅读教学中, 并非所有的课文都适合开 展 “以读促写” 教学活动。必须结合当前的写作要求和学生的需求点去 布置相关的活动。

现阶段, 初中生所接触到的写作形式主要分为: 写人、写事以及写 物, 所以, 在阅读教学中, 语文教师只需要挑选一些符合这些写作风格 的课文加以利用即可。

合理利用初中语文课本上的课文, 有效补充学生内在写作素材的不 足, 有效激发学生的写作情感和灵感, 从而最大化满足学生的写作需求,
以全面提升学生的写作能力。

\section{2 借鉴课文的语句机构, 有效组织学生开展仿写}

写作是一项较为系统化、繁琐化的工作, 有的学生之所以无从下笔 的根本原因, 就是缺乏一定的语文组织架构。万事开头难, 写作开头更 难, 笔者认为, 仿写是学生接触写作, 有效帮助学生找到写作突破口, 形成自己写作架构的重要一环。仿写的核心就是模仿, 发挥学生的模仿 能力, 对课文中的某些语句或者段落进行一定的同义词替换, 从而将课 文的语句模板, 拿来己用, 以促使学生找到属于自己的写作方式。

例如, 在教学《春》这篇课文时, 笔者就给学生截取了课文中这样 一个景点语句 “桃树、杏树、梨树, 你不让我, 我不让你, 都开满了花 赶趟儿。红的像火, 粉的像霞, 白的像雪”。首先, 帮助学生分析该语句 的结构: 涉及的主体有六个有桃树、梨树、杏树、桃花、梨花和兴杏花, 用到的修辞手法有比喻和排比; 在提醒学生对该语句进行同义词替换的 时候，可以让他们思考出三种可替换这三种树的事物，如杨树、柳树、 槐树, 切入的角度, 可以是生长的高度、枝干的形态比喻（发型）等等。

引导学生找到替换主体的一些事物, 进行简单的替换, 从而有效让 学生掌握仿写的切入点, 有效借助课文的模板, 找到符合自己写作风格 的写作形式, 只要长久进行练习, 学生的写作水平自然也会得到有效的 提升。

3 补充课文的留白部分, 引发学生的思维浪潮

语文课本上的一些语句, 作者为了整篇作品的布局谋篇, 不得不有 
选择性的删减一些环节和情节, 这些被删减的情节统称为 “留白”。语文 教师要善于利用这些课文留白, 充分利用学生的联想能力和创造能力, 组织学生对这些留白进行有效的填充, 从而有效提升学生的联想创造力, 拔高学生的写作水平。

例如, 在教学《最后一课》时, 文中提道: “我的朋友们啊, ” 他说, “我一一我一一”, 但是他哽住了, 他说不下去了。这些语句生动塑造韩 麦尔先生高大的爱国形象, 同时也展现其极大地内心悲痛。正是因为有 了这些破折号, 才让韩麦尔先生这个人物更加饱满和感人, 语文教师可 以引导学生对韩麦尔先生破折号的省略内容进行补写。引导学生联系当 时的战争背景以及对课堂以及学生的不舍, 思考当时韩麦尔先生的内心 思想, 补充他要说的话, 想要表达的情感, 从而有效提高学生的联想和 创造能力。

像这种存有留白的课文并不在少数, 有的使用省略号、破折号来进 行省略, 有的则选择用一句话, 一带而过, 这些都是可以锻炼学生联想 和想象创造能力的关键素材。只要语文教师稍加利用, 巧妙的搭桥铺路, 对相关内容进行, 引导学生将读写无缝衔接, 恰到好处的锻炼学生的写 作能力。

\section{4 扩写课文相关情节, 让课文变得更饱满}

上文提到的 “补写”, 是对具有省略标识的语句的一种简单扩写, 而 真正意义上的扩写, 则是为了全面丰腆某个人物形象和事件, 是对课文 意境的一种有效扩充。扩写多见于相关诗歌当中。诗歌多以语言精练、 语句节奏明快, 意境深远为主。一方面为了让学生快速进入课文的意境, 领悟课文所言传达的讯息, 另一方面也是进一步锤炼学生的想象能力和 创造能力, 从而有效达到内容和形式的有机统一。

例如, 在教学《木兰诗》一文时, 课文以情景交融的方式生动描述 了木兰代父从军的故事。该诗歌的故事性极强, 事件的安排也极为得当, 人物形象更是饱满, 颇具艺术感染力, 想要让学生快速理解该课文的情 感内涵, 就有必要引导学生对相关的段落进行扩写, 从而使木兰这一形 象更加深入人心。如, 木兰忽然停机不住叹息的场景, 还乡后再次身着 女儿装的情景, 都可以引导学生对其进行大刀阔斧的扩写, 如是开展, 木兰的巾帼不让须眉之气将会更加饱满, 人物形象也更加丰腫, 不仅有
效提高了学生的感悟水平, 同样也提高了学生的写作能力。

\section{5 根据课文的情感进行妙写, 全面升华写作情感}

在批阅学生的作文时, 经常可以看到类似于 “豆腐块陈列” 那种干 燥无味的文章。而拜读各位大家的文章时, 却感觉如饮一杯甘霖, 令心 情极为畅爽。其实, 这就是懂得表达情感和不懂得表达情感的区别。到 了初中阶段, 学生各方面的情感都有了一定的萌发, 并非缺乏情感, 而 是不懂得如何将内在的情感恰到好处的表达出来而已。所以, 如何巧妙 将学生内在情感牵引出来, 让学生懂得如何利用这些情感, 也成了当前 初中语文写作教学的重点。

想要有效理解课文的思想情感, 就必须搭建学生与课文内核的沟通 桥梁, 也就是产生情感共鸣。所以, 在进行相关阅读时, 语文教师就可 以以开展 “读书笔记” 的方式, 组织学生进行妙写。以原课文的情感, 有效催化出学生的内在情感, 从而激发学生的创作灵感。

例如, 在教学《秋天的怀念》《背景》等文章时, 语文教师就可以引 导学生联系自己与母亲、父亲生活场景, 引导学生回忆那种内心的温暖 和感动, 从而有效升华学生的内在情感, 激发学生的创作灵感, 写出一 篇读书笔记, 写下与亲情有关的文字; 又如, 在教学《邓稼先》《音乐巨 人贝多芬》就可以通过激发学生的对伟人形象的崇拜之感, 激发他们内 在的精神力量, 引导学生有感而发, 写下对伟大人物的崇拜之词, 开启 他们的妙写之旅。

总之, 语文课本就是一本无价的写作素材库, 在日常阅读教学中, 初中语文教师应当明确自身教学职责, 有效利用这一教学新路径, 有效 在阅读教学中渗透写作思想, 以读促写, 实现阅读与写作的有机结合, 从而不断提高学生的写作水平, 以不断提升学生的语文素养。

\section{[参考文献]}

[1] “三助” 教学在初中语文课堂中的应用 [A].刘景香,沈文东.2018 年教师教育能力建设研究专题研讨会论文集[C].2018.

[2]浅谈新时期初中语文课堂教学改革与创新[A].张俊林.2018 年教 师教育能力建设研究专题研讨会论文集[C].2018.

[3]陈宗荣.初中语文课内外阅读与作文教学的有效结合[J].新课 程,2020(37):68. 